Croatian Journal of Philosophy

Vol. XXI, No. 63, 2021

https://doi.org/10.52685/cjp.21.63.1

Received: June 6, 2021

Accepted: November 15, 2021

\title{
Argumentation as a Speech Act: A (Provisional) Balance
}

\author{
PAOLO LABINAZ \\ Department of Humanities, University of Trieste, Trieste, Italy
}

\begin{abstract}
This paper investigates whether, and if so, in what way, argumentation can be profitably described in speech-act theoretical terms. I suggest that the two theories of argumentation that are supposed to provide the most elaborate analysis of it in speech-act theoretical terms (namely van Eemeren and Rob Grootendorst's Pragma-Dialectics and Lilian BermejoLuque's linguistic normative model of argumentation) both suffer from the same two flaws: firstly, their "illocutionary act pluralism" assumption and secondly, a lack of interest in where arguing belongs in the classification of illocutionary acts. I argue that these flaws derive from the authors' reliance on an intention-based speech-theoretical framework. Finally, I adopt a deontic framework for speech acts in order to propose an alternative way of accounting for argumentation which seems to overcome the two limitations outlined above. According to this framework, argumentation may be conceived as a speech act sequence, characterized by the conventional effects brought about by the communicative moves (as illocutionary acts) of which it is composed.
\end{abstract}

Keywords: Speech act theory; argumentation; J. L. Austin; illocutionary force; verdictives.

\section{Introduction}

The goal of this paper is to investigate whether, and if so, in what way, argumentation can be profitably described in terms of speech-act theory. On the one hand, although most argumentation theorists conceive argumentation as a social and communicative activity, only a few of them have gone further by analyzing it in detail as a speech act. At the same time, while speech-act theorists have indeed referred to the act 
of arguing as a kind of illocution, they have failed to provide any systematic description of its illocutionary force. It is thus still a relatively open question whether and to what extent construing argumentation as a speech act can help shed light on its social and communicative function.

The paper is organized as follows: the next section (Section 2) considers how argumentation has been characterized as a social and communicative activity in argumentation studies. I then turn to the two most elaborate accounts which have analyzed it in terms of speech-act theory, namely van Eemeren and Rob Grootendorst's Pragma-Dialectics and Lilian Bermejo-Luque's linguistic normative model of argumentation (Section 3). After that, I discuss some of the problems associated with their (intention-based) speech-act theoretical frameworks which I believe make their accounts descriptively inadequate (Section 4). Finally, I suggest an alternative way of accounting for argumentation from a speech-act theory perspective, considering it not as a specific kind of speech act complex, but rather as a speech act sequence, characterized by the conventional effects brought about by the communicative moves (as illocutionary acts) of which it is composed (Section 5).

\section{From argument to the act of arguing}

Over the last 30 years or so, there has been a gradual shift in interest in argumentation studies from arguments as semantic structures to arguments as communicative moves (van Eemeren et al. 2014: 27-39). This shift has led argumentation theorists to focus on the conditions under which argumentation is established and carried out within different communicative contexts. Their analyses are characterized by a pragmatic approach to argumentation: communication is conceived as a goal-oriented activity, in which argumentation is used for the attainment of goals. Despite this common approach, as van Eemeren and his colleagues have pointed out (2014: 29) "as yet, there is no unitary theory of argumentation that encompasses the logical, dialectical, and rhetorical dimensions of argumentation and is universally accepted". Let us now take a brief look at some of the most significant examples of how argumentation has been defined by argumentation theorists from their own different perspectives.

According to Frans van Eemeren and Rob Grootendorst (2004: 1), argumentation is to be conceived as "a verbal, social, and rational activity aimed at convincing a reasonable critic of the acceptability of a standpoint". By focusing on the argumentative interaction between proponents and (potential) opponents of a standpoint, they elaborate an ideal model of a critical discussion, which specifies stages and rules involved in a rational dialectical procedure (van Eemeren and Rob Grootendorst 2004: 57-62). Whereas Douglas Walton (1990: 411) focuses primarily on arguments, considering them as moves occurring in a certain con- 
text of dialogue. According to him, there are different types of dialogue which are characterized by different goals (such as persuasion dialogue, negotiation, inquiry etc.) and each of these represents a different conversational context of argument use (see Walton 1998). Accordingly, argumentation is assumed to contribute to the attainment of the goal of the type of dialogue concerned. Ralph Johnson (2000: 12, 154) takes a difference stance towards argumentation, construing it as "the sociocultural activity of constructing, presenting, interpreting, criticizing, and revising arguments". An argument consists in a discourse (or text) through which an arguer aims to persuade her interlocutors of the truth of an already made claim by providing reasons in support of it. This is what Johnson considers the illative core of an argument, distinguishing it from the dialectical tier "in which the arguer discharges his dialectical obligations" (Johnson 2000: 168). Finally, David Hitchcock (2002: 326-327) has adopted a modified version of Johnson's definition of argumentation. According to him, in describing the goal of the practice of argumentation as that of persuading someone of the truth of a claim, Johnson wrongly focuses on the arguer's expected outcome, and not on the function of the practice itself. In Hitchcock's view, the purpose of argumentation is to be conceived as "reaching a shared rationally supported position on some issue" (Hitchcock 2002: 327) because it is only by conceiving its specific purpose in this way that we can avoid equating it to a rhetorically-driven communicative practice.

Whether argumentation is conceived as aimed at convincing a reasonable critic of the acceptability of a standpoint (van Eemeren and Grootendorst 2004), or at contributing to the goal of different types of dialogue (Walton 1998), or at reaching "a shared rationally supported position on some issue" (Hitchock 2002), or more simply at rationally persuading the other(s) of the truth of a thesis (Johnson 2000), all these goals are assumed to be pursued by engaging in the social and communicative activity of making arguments. In making an argument, we engage in a reasoning process: what we do is make connections between certain claims and an already made a claim in such a way as to support the latter with the former. When we present the argument to an addressee, we do so because we want to convince her that the justificatory link we have established between those claims holds. In so doing, we have performed an act of arguing. Regardless of its proper purpose, then, argumentation as a social and communicative activity necessarily involves (at least) one or more acts of arguing. This means that if we want to understand the communicative and social function of argumentation, we need to investigate the specific characteristics of this act. At this point, the first task to be dealt with is to establish what is constitutive of any communicative move that counts as an act of arguing. But one also has to identify its components: does it consist only in the claims provided in support of a certain claim, or is the claim being supported also part of it? 


\section{Argumentation as a speech act}

It is widely assumed among argumentation theorists that the framework provided by speech act theory can be of help for an in-depth investigation of the act of arguing. According to the most representative speech-act theorists, arguing is to be understood as a type of illocution. John L. Austin, the founder of the speech act theory, includes the verb "to argue" within the class of the performative verbs and considers it as denoting an expositive illocutionary act (see Austin 1975: 160-162). According to John Searle and Daniel Vanderveken (1985: 184), on the other hand, the act of arguing belongs to the class of the assertives. They point out that arguing has much in common with another member of this class, namely assuring: indeed, both are associated with the perlocutionary intention of convincing an addressee of the truth of a claim since people rely on them when someone has doubts about the truth of an already made a claim. However, only in the case of arguing does the speaker try to fulfill the perlocutionary intention by providing reasons in support of that claim. Be that as it may, neither Austin nor Searle and Vanderveken have provided a systematic description of its illocutionary force. Argumentation theorists, too (with a few notable exceptions) have not devoted much energy into making an in-depth investigation of argumentation as an illocution. In the next two sub-sections, we consider the only two theories of argumentation which, in my opinion, analyze it thoroughly in speech-act theoretical terms. We begin with the first (historically) complete analysis of argumentation as a speech act, proposed by van Eemeren and Grootendorst $(1983,1992)$ within their pragmadialectical theory. We then examine Lilian Bermejo-Luque's linguistic normative model of argumentation, which differs substantially from van Eemeren and Grootendorst's analysis (see Bermejo-Luque 2011).

\subsection{Argumentation as an illocutionary act complex}

In Van Eemeren and Grootendorst's normative model of a critical discussion, argumentation comes into play at its third stage. Indeed, argumentation is carried out after the parties involved in the discussion have established what dispute is at stake (confrontation stage) and after they have assumed the discussion roles of proponent and opponent (opening stage) (Van Eemeren and Grootendorst 1992: 35).

Based on a revised version of Searle's speech act theory (see Searle 1969, 1979), Van Eemeren and Grootendorst (1983: 39) describe argumentation as an illocutionary act complex (also speech act complex) consisting of a certain number of "elementary" illocutionary acts (more specifically, assertive speech acts) that stand "[...] in a justifying or refuting relation to an expressed opinion (which consists of statements acting as a claim or conclusion)". ${ }^{1}$ A speaker usually performs a speech

${ }^{1}$ The expressed opinion can be any proposition because it "may refer to facts or ideas [...] actions, attitudes, and so on" (van Eemeren and Grootendorst 1983: 5). 
act of this kind in reaction to an addressee either expressing doubts about a claim previously made by her or putting forward a claim contradicting it. When this happens, in order to defend her claim, the speaker advances one or more assertive speech acts in its support. It is the complex of these assertive speech acts that, taken together, constitutes the performance of the complex illocutionary act of arguing. From a critical discussion perspective, this act should be aimed at contributing to resolving the difference of opinion as to the claim at issue between speaker and addressee (van Eemeren and Grootendorst 1992: 28-30).

Van Eemeren and Grootendorst (1992: 29) point out that the main difference between the illocutionary act complex of argumentation and the "elementary" illocutionary acts composing it is that while the latter's communicative function operates at the sentence level, that of the former works at some higher textual level. However, they hold that it has the same sort of felicity conditions as an "elementary" illocutionary act. In formulating its felicity conditions, van Eemeren and Grootendorst take inspiration from Searle's distinction between propositional, preparatory, sincerity and essential conditions, dividing them into identity and correctness conditions. As to the identity conditions, which comprise Searle's propositional and essential conditions (see Searle 1969: 57-61), these must be satisfied for a constellation of assertive speech acts to be recognized as the felicitous performance of the illocutionary act complex of argumentation. When speaking of correctness conditions, van Eemeren and Grootendorst refer to what is required for the performance of this act complex to be regarded as appropriate. These conditions include Searle's preparatory condition as well as what they call the "responsibility condition", which replaces Searle's sincerity condition in order to emphasize the commitment one incurs by virtue of being recognized as arguing (van Eemeren and Grootendorst 1992: 30-33).

Let us consider how these felicity conditions apply to the illocutionary act complex of argumentation.

As to the identity conditions, this illocutionary act is felicitously performed (and can thus be recognized as such) if the following two conditions are met:

1. Propositional content condition: utterances $1,2, \ldots, n$ constitute the elementary speech acts $1,2, \ldots, n$, in which a commitment is undertaken to the propositions expressed.

2. Essential condition: the performance of the constellation of speech acts that consists of the elementary speech acts $1,2, \ldots, n$ counts as an attempt by the speaker to justify $p$, that is to convince the listener of the acceptability of his standpoint with respect to $p$.

Furthermore, the performance of the illocutionary act complex of argumentation is regarded as appropriate if the following conditions are met: 
3. Preparatory conditions:

a. The speaker believes that the listener does not accept (or at least not automatically or wholly accept) his standpoint in respect to $p$.

b. The speaker believes that the listener is prepared to accept the propositions expressed in the elementary speech acts 1 , $2, \ldots, n$.

c. The speaker believes that the listener is prepared to accept the constellation of elementary speech acts $1,2, \ldots, n$ as an acceptable justification of $p$.

4. Responsibility conditions:

a. The speaker believes that his standpoint with respect to $p$ is acceptable.

b. The speaker believes that the propositions expressed in the elementary speech acts $1,2, \ldots, n$ are acceptable.

c. The speaker believes that the constellation of the elementary speech acts $1,2, \ldots, n$ is an acceptable justification of $p$. (van Eemeren and Grootendorst 1992: 31)

When only the identity conditions are met, the illocutionary act complex of argumentation counts as felicitous, but is regarded as failing to convince the listener of the acceptability of the standpoint in support of which the act has been performed. If the identity conditions are not met either, then the constellation of elementary assertive illocutionary acts would not be recognized as counting as an attempt to argue in favor of a certain standpoint.

It is to be noted that van Eemeren and Grootendorst (1992: 26-27, 33) distinguish between the communicative and interactional aspects involved in the illocutionary act complex of argumentation. While the communicative aspect has to do with the speaker's communicative intention, that is, to make one's audience understand that in making a certain constellation of statements she intends to justify a previously expressed opinion, its interactional aspect is concerned with convincing the audience of the acceptability of that opinion. In van Eemeren and Grootendorst's view, the interactional aspect links the speech act of arguing with the perlocutionary act of convincing. A listener is said to be convinced when she is prepared to accept the expressed opinion to which the speaker's argument relates. According to them, this acceptance amounts to the perlocutionary effect conventionally associated with argumentation (van Eemeren and Grootendorst 1983: 65-69). This effect must be an intentional one on the part of the speaker: it requires a full understanding of the speech act and is "[...] partly dependent on rational considerations on the part of the listener" (van Eemeren and Grootendorst 1983: 28). 


\subsection{Argumentation as a second-order illocutionary act complex}

Lilian Bermejo-Luque (2011: 62), too, considers argumentation as a composite illocutionary act, but conceives it as consisting of two distinct illocutionary acts, namely the act of adducing (a reason) and that of concluding (a target-claim). ${ }^{2}$ In her view, these are second-order illocutionary acts, because "they can only be performed by means of first order speech-acts [...]" (Bermejo Luque 2011: 60). More specifically, two first-order speech acts count as an act of adducing $(R)$ and an act of concluding $(C)$, respectively, if an addressee attributes to the speaker performing them an implicit inference-claim $(I)$ of the form "if $R$ (the content of the reason adduced), then $C$ (the content of the targetclaim)". In doing so, the addressee interprets the speaker as performing the "second-order illocutionary act complex" of arguing. Consider the following example by Bermejo-Luque (2011: 60). When uttering something like "I promise I'll take care, so don't worry", at first sight the speaker appears to be performing the first-order illocutionary acts of promising and requesting, respectively. However, if the addressee takes it that these two illocutionary acts are connected with each other by an inference-claim of the type "If I promise I'll take care, then you should not be worry", then "I promise I'll take care" would count as the second-order illocutionary act of adducing (that the speaker commits herself to take care) and "Don't worry" as the second-order illocutionary act of concluding (that the addressee should not be worried), respectively. In uttering "I promise I'll take care, so don't worry", then a speaker would normally be regarded as arguing.

In order to account for the illocutionary force of the second-order illocutionary act complex of argumentation, Bermejo-Luque (2011: 61) relies on the Speech-Act Schema developed by Ken Bach and Robert Harnish (1979), considering it better suited to this job than van Eemeren and Grootendorst's speech-act theoretical framework. Bach and Harnish's Speech-Act Schema constitutes an inferential pattern that an addressee has to follow in order to determine the content and the force of an illocutionary act (Bach and Harnish 1979: 4-7). Most importantly, this inferential pattern is based upon three presumptions: the linguistic presumption, the communicative presumption and the presumption of literalness (Bach and Harnish 1979: 7, 12). Here, we are interested in the communicative presumption. According to this, whenever a speaker utters a certain sentence, she is doing so with some recognizable intention. Were this not so, it would be impossible, or nearly impossible, to identify the illocutionary force of her utterances. According to Bermejo-Luque (2011: 61), attributing to a speaker the implicit inference-claim (I) of the form "if $R$, then $C$ " to which we

2 According to Bermejo-Luque (2011: 59), van Eemeren and Grootendorst's analysis differs from hers because, by speaking of argumentation as consisting of the assertive speech acts put forward in support of a previously made claim, they erroneously equate it to the act of adducing. 
referred previously is based on a similar presumption: it amounts to the mutual belief (of both addressee and speaker) that the speaker, together with performing the second-order speech acts of adducing $(R)$ and of concluding $(C)$, is also intending to implicitly assert "if $R$, then $C$ ' (argumentative presumption). Bermejo-Luque (2011: 62) points out that an addressee makes this presumption whenever the speaker uses epistemic qualifiers such as "probably," "necessarily," "evidently" and so on, or expressions like "so," "therefore," "since," and "consequently". It is precisely the fact that these expressions are attached to some firstorder speech acts (constative ones, in particular) that usually prompt the addressee to interpret such speech acts as second-order speech acts constituting the illocutionary act complex of argumentation.

Given the conventional nature of illocutionary acts, Bermejo-Luque (2011: 68-69) too acknowledges that, as van Eemeren and Grootendorst have observed, there must be some necessary and jointly sufficient conditions the satisfaction of which makes a certain performance count as an act of arguing. Following Searle's distinction between preparatory, sincerity and essential conditions, she formulates the following conditions:

Preparatory conditions:

(i) $S$ believes that a claim $R$, having such and such pragmatic force, may be taken to be correct by $L$

(ii) It makes sense to attribute to $S$ a conditional claim, with a certain pragmatic force, whose antecedent is " $R$ is correct," and whose consequent is " $C$ is correct"

(iii) $\mathrm{S}$ takes the correctness of a claim $\mathrm{C}$ to be in question within the context of the speech-act

Propositional content conditions:

(v) The content of the reason is that a claim $R$ ' is correct

(vi) The content of the target-claim is that a claim $C^{\prime}$ is correct

Sincerity conditions:

(vii) $S$ believes the propositional content of $R$ in a certain way and to a certain extent, namely, the way and extent that correspond to the pragmatic force of the claim $R$,

(viii) $S$ believes that $R$ being correct is a means to show that a targetclaim $C$ is correct

(ix) $S$ believes the propositional content of $C$ in a certain way and to a certain extent, namely, the way and extent that correspond to the epistemic pragmatic force of the target-claim $C$

Essential conditions:

(x) Adducing $R$ with such and such pragmatic force is a means to show that a target-claim $C$ is correct

(xi) $S$ aims to show that a target-claim $C$ is correct. (Bermejo-Luque 2011: 70-71)

Although, according to Bach and Harnish, felicity conditions have no role to play in their Speech Act Schema, Bermejo-Luque thinks that it 
can be a useful interpretative tool for considering whether conditions (i)-(xi) have been fulfilled in a certain situation.

If we look at the essential conditions, which specify what constitutes the performance of a given type of speech act, we notice that, according to Bermejo-Luque, what characterizes the act of arguing amounts to its "[...] being aimed at showing a target-claim to be correct-that is, aimed at justifying" (Bermejo-Luque 2011: 55). It is this goal that "[...] conventionally renders any piece of communication argumentation" (Bermejo-Luque 2011: 58). This means that an audience recognizes the act of arguing being made "by recognizing a speaker's communicative intention of showing a target-claim to be correct" (Bermejo-Luque 2011: 24), regardless of her ulterior (perlocutionary) intentions. In contrast with the standpoint of van Eemeren and Grootendorst, Bermejo-Luque does not consider the goal of convincing to be a necessary condition of the act of arguing since it is only one of the possible goals that we may pursue by means of it (Bermejo-Luque 2011: 59). However, argumentation as a persuasive device plays a fundamental role in communication: it aims at achieving "[...] rational persuasion rather than mere conviction" (Bermejo-Luque 2011: 58), since its persuasive power depends on the reasons provided in support of the target-claim.

\section{Illocutionary act pluralism and illocutionary classes}

The two accounts presented above have the great merit of drawing attention to the speech act status of argumentation. Both accounts focus on the illocutionary aspect of the act of arguing and conceive of it as comprising the speaker's having a certain communicative intention (basically, the intention of arguing), meant to be recognized as such by the audience. While van Eemeren and Grootendorst assume that to argue is to intend to make one's audience understand that in making one or more assertive speech acts one is attempting to justify a certain standpoint in order to convince them of its acceptability, Bermejo-Luque foregrounds the intention to show that the target-claim is correct or to justify it. Both accounts also pay some attention to the perlocutionary goal typical of arguing: in the former, the association of arguing with the perlocutionary goal of convincing the audience of the acceptability of the target-claim follows on directly from the way in which the communicative intention of arguing is specified, while in the latter, the act of arguing, the main aim of which is justificatory, is granted an additional persuasive function (which, however, does not amount to a condition for its performance). Furthermore, there is a fundamental difference in the way the two accounts characterize the elements composing the complex illocutionary act of arguing: van Eemeren and Grootendorst identify this act with the reason(s) presented in support of the target claim, whereas Bermejo-Luque refers to it as the core unit of reason(s) and target claim. 
While I have some sympathy for van Eemeren and Grootendorst's and Bermejo-Luque's general approach to analyzing argumentation as a speech act, it seems to me that the speech-act theory frameworks on which they base their analyses suffer from two significant drawbacks common to both: the first regards the assumption of "illocutionary act pluralism" underlying both analyses, while the second has to do with where to place arguing in the classification of illocutionary acts. In my opinion, these problems must be addressed if we hope to gain an understanding of the actual explanatory power of an analysis of argumentation as a speech act.

Let me start with the issue related to the "illocutionary act pluralism" assumption, according to which an utterance token can carry out more than one illocutionary act. This assumption is at the core of both of the analyses presented above: van Eemeren and Grootendorst (1983: 32) state explicitly that "sentences uttered in argumentation in fact have two illocutionary forces simultaneously" and Bermejo-Luque (2011: 59, 60) agrees with them by defining the illocutionary act of arguing, as well as the illocutionary acts composing it (i.e., adducing and concluding), as "second-order" illocutionary acts. Indeed, according to their analyses, assertive (or, using Bermejo-Luque's terminology, constative) speech acts can be conceived in certain conditions as also having a different illocutionary force, and thereby another communicative function. While assertive speech acts are aimed at presenting their propositional content as true, when they are involved in argumentation, they are also designed to either express a certain standpoint or provide support for it.

In traditional speech act literature, the two most studied cases of illocutionary plurality are those in which (i) illocutionary force indicators either contained in a certain utterance or accompanying it (in the form of paralinguistic features) are taken to indicate one illocutionary force or another (e.g., the verb in the future tense in a sentence such as "I will call a lawyer" may be taken to indicate a promise, a warning or even a prediction) and (ii) utterances with linguistic features which indicate a certain illocutionary force (e.g., the interrogative form for a question such as "Can you pass the salt, please?") are interpreted as performing a different illocutionary act (e.g., an indirect request), the so-called "indirect speech acts" (Searle 1979: 30-57). In both of these cases, as well as in those involving argumentation, a crucial role is played by the addressee's uptake. While, on the one hand, the speaker may do everything possible to get the addressee to understand the illocutionary force of her utterance, on the other, recognition of the illocutionary act the former is purporting to perform must always be ratified by the latter. Indeed, the addressee's recognition of the speaker's communicative intention is partly constitutive of its fulfilment. If cases of illocutionary plurality such as (i) can be explained locally (that is, depending from time to time on the distinguishable features of the 
context of utterance), cases of indirect speech acts and those involving argumentation require something more, and namely accounting for the general possibility of illocutionary plurality. In the standard account of indirect speech acts, illocutionary plurality is explained by identifying a primary illocutionary act (the indirect request) which is performed through the performance of a "secondary" (or literal) elementary illocutionary act (the question) (Searle 1979: 33-36). However, as Searle himself explains, in such cases the speaker is recognized as having the communicative intention to perform only the "primary" illocutionary act. What about cases involving argumentation? Can the standard account of indirect speech acts be applied to them? It seems to me that it cannot, for two main reasons. Firstly, indirect speech acts are elementary (or first-order) illocutionary acts (such as requests, rejections and so on), whereas in the case of argumentation, there is a leap from elementary (or first-order) illocutionary acts to a composite (or second-order) illocutionary act. Secondly, indirect speech acts involve the speaker having the communicative intention to perform only the "primary" illocutionary act, while according to the accounts presented above, when arguing, a speaker has the communicative intention(s) of performing both elementary (or first-order) and composite (or secondorder) illocutionary acts. This means that when attempting to argue, a speaker should be expressing two distinct communicative intentions: the one associated with the performance of each of the assertive (or constative) speech acts which make up the illocutionary act complex of arguing, and the one associated with its performance. But how is it possible to express two distinct communicative intentions when issuing the same utterance? It may be conceded that the same sentence uttered at two different points in the same conversation can express different communicative intentions. If so, its utterances will be the vehicle of different illocutionary acts at different stages in the conversation. But that is not what van Eemeren and Grootendorst and Bermejo-Luque seem to suggest: indeed, as stated above, both sides are in agreement that "sentences uttered in argumentation in fact have two illocutionary forces simultaneously". What is needed, then, is an explanation of how an utterance token may be recognized as having two different communicative intentions and hence two different illocutionary forces at the same time. Moreover, it remains to be seen whether this condition only regards sentences uttered in the attempt to argue, or can be expanded to include sentences in discourses that are not argumentative. Indeed, if it only concerns sentences uttered in argumentation, one might think that what both van Eemeren and Grootendorst and Bermejo-Luque have provided is simply an ad hoc explanation of how some assertive (or constative) speech acts (taken together) can count as the performance of the illocutionary act complex of arguing.

The second problem concerns the place of arguing in the classification of illocutionary acts. It is widely recognized among speech act theo- 
rists that illocutionary acts of different kinds can be divided into different classes (Searle 1969: 66-67, 1979: 1-29, Bach and Harnish 1981: 39-59, 108-119; for a general overview, see Kissine 2013). Surprisingly, neither van Eemeren and Grootendorst nor Bermejo-Luque suggest to which class of illocutionary acts arguing may belong. Since, according to them, it is composed of assertive (or constative) speech acts, one might think that it might be conceived as belonging to the assertive class. But this is not possible. Indeed, as said before, van Eemeren and Grootendorst hold that there are two illocutionary forces simultaneously associated with the sentences involved in argumentation: one is of the assertive kind, while the other is the force characteristic of the act of arguing. This means that the two illocutionary forces cannot coincide. Accordingly, arguing cannot belong (if not indirectly) to the class of the assertives. Another possibility is that the illocutionary act of arguing belongs to a class of illocutionary acts whose members are all illocutionary act complexes (or second-order illocutionary acts). However, an illocutionary act's being composed of more than one element is not a relevant criterion for identifying the members of a certain class. Think of another potential member of this class, namely explaining. It has something in common with arguing: both of them are composed of more than one element (explananda/explanandum, and reason(s)/target claim, respectively) and they also share some of the same linguistic indicators, such as the connectives "because" and "since" (which can be used as indicators for argumentation and for explanation), as well as "therefore" which, as well as indicating the conclusion of an argument, can also be used in explanations. However, these are superficial similarities. If we look at their communicative function, the differences between them become very evident. Indeed, when we have to give an explanation for some fact or event, and this occurs when we recognize that the addressee has some cognitive need or interest with respect to that fact or event, we do not take its occurrence (or the statement asserting that it occurs) as problematic. Instead, as we already know, in the case of argumentation, we aim to show that a certain claim (which has been questioned or may be questioned by someone) is well-grounded. It would therefore seem arduous to place argumentation and explanation in the same class of illocutionary acts, and the same might be said of other illocutionary act complexes (if they exist). If we rely, then, on the speech-act theoretical frameworks proposed by van Eemeren and Grootendorst and Bermejo-Luque, respectively, we must assume that the illocutionary act complex of arguing is situated outside any classification of illocutionary acts. But this is not in line with the most elaborate attempts to theorize about speech or illocutionary acts, all of which aim to establish very clear boundaries between different kinds of illocutionary acts.

Since the accounts of argumentation as a speech act proposed by van Eemeren and Grootendorst and Bermejo-Luque, respectively, do not seem to have the resources to deal with the problems just discussed, 
I think it might be concluded that they are not descriptively adequate, at least from a speech-act theoretical perspective.

\section{Argumentation as a speech act sequence}

In this section, I would like to suggest an alternative way of accounting for argumentation from a speech-act theoretical perspective. To do so, in place of the intention-based framework for speech acts assumed by van Eemeren and Grootendorst and Bermejo-Luque, I shall adopt a deontic one. ${ }^{3}$ According to the intention-based framework, the core illocutionary effect of a speech act consists of bringing about the addressee's recognition that the speaker intends to perform a certain kind of speech act, while the deontic one characterizes speech acts as having illocutionary effects that go beyond the "securing of uptake" (Sbisà 2007, 2009). These are conventional effects which come into being in virtue of intersubjective (and therefore social) agreement, ${ }^{4}$ made possible by the securing of uptake. According to the deontic framework, an illocutionary act consists in the achievement of its characteristic conventional effect, which can be described in terms of deontic modal attributes (e.g. rights or authority, obligations or needs and so on) to be assigned or unassigned to the relevant participants in the communicative situation at hand (Sbisà 1984, 2006: 164-167). More specifically, this effect amounts to a change in the deontic dimension of their interpersonal relationship, since it concerns what they are entitled or obliged or committed to do with respect to each other.

As I will try to show, the deontic framework adopted here can help overcome the two problems discussed in the previous section by considering arguing not as a specific kind of speech act complex, but as a speech act sequence characterized by the conventional effects brought about by the illocutionary acts of which it is composed. While one the one hand, argumentation requires a complex sequence of speech acts to be recognized as such on the other, any speech act involved in such a sequence may be thought of as bringing about a change in the deontic statuses of the participants in a communicative situation, thereby establishing what can or must (or cannot or must not) be done in the next stage of the sequence. At the same time, that speech act is performed against a normative background established by the performance of the speech act preceding it (if there has already been one).

Let us now consider how argumentation as a speech act sequence may unfold using the deontic approach to speech acts adopted here. First of all, this requires identifying which type of illocutionary act may be the initiator of the sequence. Relying on Austin's illocutionary

3 This deontic framework is grounded on J.L. Austin's conception of the illocutionary act and its effects as further elaborated by Marina Sbisà (see Austin 1975: 116-117; Sbisà 1984, 2006).

${ }^{4}$ It is to be noted that agreement can be presumed to occur by default, that is, in the absence of evidence to the contrary. 
classes (1975: 150-163), we can assume that it is the verdictive type. Austin characterizes verdictives as consisting in "[...] the delivering of a finding, official or unofficial, upon evidence or reasons" regarding "something-fact, or value-which is for different reasons hard to be certain about" (Austin 1975: 151, 153). ${ }^{5}$ There are various subtypes of verdictives, ranging from official and institutional to informal and conversational ones, each of which can in principle be the initiator of an argumentative sequence. Indeed, there is usually a verdictive at the core of argumentation, the correctness of which (truth, rightness, etc.) is focused on as being problematic. ${ }^{6}$ In fact, a speaker performing a verdictive presents herself as willing to take on responsibility for the correctness (truth, fairness etc.) of the judgment issued and as acting on the basis of a publicly recognizable cognitive competence (Sbisà 2019: 10-13). When a verdictive is performed, at least two possible moves become available to the audience: the preferred default option is agreement, while disagreement is the dispreferred. Both of them involves different rights or entitlements and commitments or obligations for the participants in the communicative situation. As for the audience, the performance of a verdictive assigns to them a double entitlement that is describable as a "can". On the one hand, when agreement occurs, ${ }^{7}$ the audience can (is entitled to) issue further, related verdictives on the basis of the received one, or to use its content (in whole or in part) as a premiss in reasoning or as a ground for decisions. On the other hand, since verdictives are by definition open to objections, the audience can (is entitled to) challenge the verdictive issued by asking for the speaker's grounds for it (by expressing doubts, presenting a rebuttal and so on), thereby focusing on the commitment one incurs in performing a verdictive. However, being aware that anyone in the audience can ask for her grounds for performing a verdictive, the speaker may also try to prevent disagreement by advancing reasons in support of the verdictive she is about to perform. In terms of deontic states, the commitment one incurs in performing a verdictive can be specified as an "ought": it amounts to the speaker's obligation to show that a verdictive whose correctness has been questioned (or may be questioned) by an addressee, is well-grounded. So, arguing comes into play either when the speaker's verdictive is appropriately challenged or when the

${ }^{5}$ Bach and Harnish (1979: 109-119) too, identify a class of verdictives but delimit its members to official findings. Conceived in this way, verdictives are part of what they call "conventional" illocutionary acts: these are acts that are performed with the intention of following a convention which bring about changes in institutional states of affairs.

${ }^{6}$ Also in the case of official or institutional verdictives, the judgment issued can be informally criticized as problematic, even though what they establish as being the case cannot be changed (except by means of some other official or institutional speech act).

${ }^{7}$ Agreement can be explicit, but most of the time it is tacit (due to the absence of any manifestation of disagreement). 
speaker herself would like to try to prevent disagreement with the audience. When this happens, the speaker is expected to issue other verdictives which are claimed or supposed to vouch for the correctness (truth, fairness etc.) of the targeted verdictive. In turn, the issuance of these verdictives will affect the deontic statuses of the participants in the communicative situation at hand because they will bring about the characteristic illocutionary effect described above. It is the sequence of these speech acts that constitutes a case of argumentation. Argumentation may thus be conceived as a speech act sequence made up of two or more verdictives, where one is supported (warranted, justified or established) by the other(s). Clearly, this sequence can be intertwined with other illocutionary acts (such as challenges, objections, verdictives expressing a counter-standpoint etc.). What matters to us is that each move as an illocutionary act involved in this sequence is constrained by the illocutionary effect of the one preceding it: in turn, its illocutionary effect establishes what the legitimate options for the next move are.

It is certainly true, as van Eemeren and Grootendorst point out, that argumentation can be conceived as occurring at a "higher textual level" than its components, but it seems to me that this is not enough to treat it as an independent speech act complex. Since the unfolding of argumentation as a speech act sequence is distinguished by the characteristic effect of the verdictives composing it, its illocutionary force is inherited from them. Indeed, just as when issuing a verdictive, a speaker commits herself to the correctness (truth, fairness etc.) of her judgment, so too, a speaker giving support to a verdictive already made is committed to the correctness or soundness of the argument presented, if and when its correctness or soundness (or its underlying criteria) is appropriately challenged. When a challenge is issued, the speaker advancing the argument is bound to justify her moves by defending the verdictives the argument consists of, as well as the argument itself. In particular, when defending an argument, the speaker has to make explicit the warrant licensing the move from the verdictives presented in support of the targeted verdictive to the targeted verdictive itself, as well as the backing for the warrant (Toulmin 2003: 97-107). However, warrants are typically not explicitly asserted, but retrievable (mainly by conventional implicatures generated by expressions such as "so", "therefore", "hence" or by particularized conversational implicature) insofar as an addressee is actually interested in evaluating the justificatory link that the speaker assumes to hold between the targeted verdictive and the verdictive(s) presented in its support (see also Labinaz and Sbisà 2018: 622-623). Since the warrant is typically conveyed by means of an implicature, and since to be recognized as such, an implicature does not need to meet any felicity conditions, it cannot be equated with an implicit assertion, as Bermejo-Luque has claimed (see Section 3.1) Only once the warrant is made explicit can it be dealt with as the content of an assertion or more generally, of a verdictive. Faced with the warrant, the audience can (is entitled to) either accept 
the justificatory link it establishes or challenge it by asking for the speaker's grounds for taking it to be true. In response to this challenge, the speaker is expected to articulate the backing for the warrant of her argument. It is to be noted that backings are usually not explicitly asserted, since they often lie in the speech event's common ground (see also Labinaz and Sbisà 2018: 622-623). In this case, too, its content must be made explicit and conveyed by means of a verdictive, thereby committing the speaker to its correctness.

To sum up, it might be said that argumentation as a speech act sequence can be characterized through the normative relations that hold between the speech acts composing it. It starts with the commitment a speaker incurs in performing a verdictive which constrains how she must react if someone challenges the judgment issued (even though that commitment obviously does not constrain what the verdictive should be about in the first place). If the speaker seeks to discharge this commitment, as opposed to retracting it, then she must provide an argument by performing some additional verdictives acting as reasons in support of the verdictive already made. It is clear that not all verdictives occur within an argumentative sequence, but all of them can potentially be part of one (see also Brandom 1994: 167-168). Every time an addressee challenges a verdictive, or the speaker believes that he may do so, the latter is expected to argue for the correctness of her verdictive in order to resolve the disagreement with the former and move towards the preferred communicative option, namely agreement. In this respect, as Sally Jackson and Scott Jacobs have suggested, arguing may be said to play a key role in disagreement regulation (Jacobs and Jackson 1982: 226-227; Jacobs 1986).

\section{Concluding remarks}

In this paper, I have examined whether, and if so, in what way, argumentation can be profitably described in speech-act theoretical terms. I have suggested that the two theories of argumentation that are supposed to provide the most elaborate analysis of it in speech-act theoretical terms (namely van Eemeren and Rob Grootendorst's PragmaDialectics and Lilian Bermejo-Luque's linguistic normative model of argumentation) both suffer from the same two flaws regarding their "illocutionary act pluralism" assumption and the lack of interest in where to place arguing in the classification of illocutionary acts. In themselves, these two flaws are not fatal, but they significantly weaken the explanatory power of the two theories, at least from a speech-act theoretical perspective. I have proposed that this derives in part from their reliance on an intention-based speech-theoretical framework. As argued in Section 5, a more promising path presents itself if we turn to a deontic framework for speech acts, which seems able to overcome the two limitations outlined above. Based on this framework, we can conceive argumentation as a speech act sequence characterized by the 
conventional effects brought about by the verdictive illocutionary acts composing it: conversational moves (as illocutionary acts) involved in such a sequence are constrained by the illocutionary effects of those preceding them: in turn, their illocutionary effects establish what the legitimate options for the next move are. Since, according to the deontic framework, illocutionary force is not to be equated with the speaker's intention, there is no need to attribute multiple intentions to the speaker when accounting for the illocutionary force of argumentation, as suggested by van Eemeren and Grootendorst's and BermejoLuque's analyses. Furthermore, since the unfolding of argumentation as a speech act sequence depends on the characteristic conventional effects of the verdictives involved, we may say that it inherits its illocutionary force from them. This said, I am aware that, before drawing definite conclusions about the speech act status of argumentation, much more should be done to further develop this analysis in terms of deontic states and apply it to real cases of argumentation.

\section{References}

Austin, J. L. 1975. How to Do Things with Words. Oxford: Oxford University Press.

Bach, K., and Harnish, R. 1979. Linguistic Communication and Speech Acts. Cambridge: The MIT Press.

Brandom, R. 1994. Making It Explicit: Reasoning, Representing, and Discursive Commitment. Cambridge: Harvard University Press.

Bermejo Luque, L. 2011. Giving Reasons. A Linguistic-pragmatic Approach to Argumentation Theory. Dordrecht: Springer.

Eemeren van, F. H., and Grootendorst, R. 1983. Speech Acts in Argumentative Discussions. Dordrecht: Foris.

Eemeren van, F. H., and Grootendorst, R. 1992. Argumentation, Communication, and Fallacies: A Pragma-Dialectical Perspective. Hillsdale: Lawrence Erlbaum.

Eemeren van, F. H., and Grootendorst, R. 2004. A Systematic Theory of Argumentation: The Pragma-dialectical Approach. Cambridge: Cambridge University Press.

Eemeren van, F. H., Garssen, B., Krabbe, E., Snoeck Henkemans, F. A., Verheij, B., Wagemans, J.H. 2014. Handbook of Argumentation Theory. Dordrecht: Springer.

Hitchcock, D. 2017. On Reasoning and Argument: Essays in Informal Logic and Critical Thinking. Dordrecht: Springer.

Kissine, M. 2013. "Speech Act Classifications." In K. Turner and M. Sbisà (eds.). Pragmatics of Speech Actions. Berlin: de Gruyter Mouton: 173-201.

Jacobs, S. 1986. "The Management of Disagreement in Conversation." In R. Grootendorst, A. J. Blair and C. S. Willard (eds.). Argumentation: Across the Lines of Discipline. Dordrecht: Foris: 229-240.

Jacobs, S., Jackson, S. 1982. "Conversational Argument: A Discourse Analytic Approach". In Cox, R. J., Willard, C. A. (eds.), Advances in Argumentation Theory and Research. Carbondale: Southern Illinois University Press: 205-237. 
Johnson, R. H. 2000. Manifest Rationality. A Pragmatic Theory of Argument. Mahwah: Lawrence Erlbaum.

Labinaz, P. and Sbisà, M. 2018. "Argumentation as a Dimension of Discourse: The Case of News Articles." Pragmatics \& Cognition 25 (3): 602-630.

Sbisà, M. 1984. “On Illocutionary Types.” Journal of Pragmatics 8: 93-112.

Sbisà, M. 2006. "Communicating Citizenship in Verbal Interaction: Principles of a Speech Act Oriented Discourse Analysis." In: H. Hausendorf and A. Bora (eds.). Analysing Citizenship Talk. Social Positioning in Political and Legal Decision-Making Processes. Amsterdam: John Benjamins, Amsterdam: 151-180.

Sbisà, M. 2007. "How to Read Austin." Pragmatics 17: 461-473.

Sbisà, M. 2009. "Uptake and Conventionality in Illocution." Lodz Papers in Pragmatics 5: 33-52.

Sbisà, M. 2019. "Assertion among the Speech Acts". In S. Goldberg (ed.). The Oxford Handbook of Assertion. Oxford: Oxford University Press. DOI: 10.1093/oxfordhb/9780190675233.013.7.

Searle, J. R. 1969. Speech Acts: An Essay in the Philosophy of Language. Cambridge: Cambridge University Press.

Searle, J. R. 1979. Expression and Meaning. Cambridge: Cambridge University Press.

Searle, J. R., Vanderveken, D. 1985. Foundations of Illocutionary Logic. Cambridge: Cambridge University Press.

Toulmin, S. 2003. The uses of argument. Updated edition. Cambridge: Cambridge University Press. First edition 1958.

Walton, D. 1990. "What is Reasoning? What is an Argument?" Journal of Philosophy 87: 399-419.

Walton, D. 1998. The New Dialectic: Conversational contexts of argument. Toronto: University of Toronto Press. 